\title{
Pengaruh kualitas pelayanan terhadap kepuasan nasabah pada Islamic Bank Of Thailand Branch Bannangstar Province Yala
}

\author{
Adinan Yahring $^{1^{*}}$ \\ ${ }^{1}$ Pogram Pascasarjana Administrasi Bisnis, Fakultas Ilmu Sosial dan Ilmu Politik Universitas Islam Riau \\ *Correspondent email : namwan7711@gmail.com
}

\begin{abstract}
The public's assessment of the bank is influenced by how the community perceives the bank's product or service received. Providing high quality service is a must to achieve customer satisfaction. For customers, quality of service and customer satisfaction comes from organized service. In simple terms, financial performance actually comes from customer loyalty. Loyal customers can save up to four to five times the cost of acquiring a new customer. This reality is a challenge in itself for the banking world, namely how to create customer desire to use the company's products and service providers and to build close relationships with the service community. The purpose of this study was to analyze the quality of service and community satisfaction of the Islamic Bank of Thailand Branch Bannangstar Province Yala and its effects. The method used is descriptive and quantitative methods; The technique of collecting data is interview, observation, questionnaire and documentation. This study concludes that based on the results of filling out the questionnaire by the research objects of this study regarding the quality of service, it is concluded that the service community feels very satisfying with the quality of service provided at the Islamic Bank of Thailand Branch, Bannangstar Province Yala. Based on the results of filling out the questionnaire by the research objects of this study, the satisfaction of the service community was also very satisfying because it had received good service at the Islamic Bank of Thailand Branch Bannangstar Province Yala. From the results of data processing, it is known that the quality of service has a significant effect on the variable customer satisfaction of the Islamic Bank of Thailand Branch Bannangstar Province Yala.
\end{abstract}

Keywords: Influence, Service Quality, Customer Satisfaction

\section{PENDAHULUAN}

Kondisi persaingan antar perusahaan yang semakin kompetitif mengharuskan setiap pengusaha mengkaji ulang strategi yang digunakannya agar tidak kehilangan pelanggannya dan demi mencapai keunggulan daya saing yang berkelanjutan. Usaha perusahaan dalam memasarkan hasil produksinya, tak bisa lepas dari kualitas pelayanan yang diberikan. Persoalan kualitas dalam dunia bisnis kini sudah menjadi suatu keharusan bagi perusahaan agar ia dapat tetap survive dalam bisnisnya. Apabila dahulu kualitas masih menjadi senjata agar perusahaan dapat memenangkan persaingan, namun kini hampir semua perusahaan, terlebih perusahaan jasa dapat memberikan kualitas yang sama, tentu saja persoalan kualitas bukanlah menjadi salah satu senjata andalan bersaing. Kualitas kini ibarat tiket masuk ke dalam gelanggang persaingan bisnis bila perusahaan ingin tetap survive.

Produk tabungan menjadi produk paling memikat bagi bank untuk memperkuat fungsi penghimpunan dana bank. Misalnya tabungan dengan bunga dihitung berdasar saldo harian yang diakumulasikan setiap akhir tahun (tabungan bunga harian), tabungan yang memberikan hadiah dengan undian setiap beberapa bulan sekali (tabungan berhadiah), berbagai fasilitas pembayaran dan lain-lain. Mencermati banyaknya jumlah bank yang menawarkan jenis-jenis tabungan baru dengan serangkaian atribut yang melekat itu menyebabkan persaingan antar bank untuk menarik nasabah semakin meningkat. Banyak faktor yang menentukan loyalitas seseorang dalam memilih bank sebagai tempat menabung, seperti kualitas pelayanan, lokasi, kepuasan nasabah, hadiah yang diberikan, frekuensi penyaringan hadiah, dan bonafiditas bank.

Penilaian masyarakat terhadap bank dipengaruhi oleh bagaimana masyarakat tersebut memaknai produk bank atau pelayanan yang diterima. Memberikan layanan yang berkualitas tinggi adalah suatu 


\section{SYNERGY}

Vol 1, No 2, Oktober 2021, p. 58-61

Jurnal Bisnis dan Manajemen

keharusan untuk mencapai kepuasan pelanggan. Bagi pelanggan, kualitas pelayanan dan kepuasan pelanggan berasal dari layanan yang terorganisir. Secara sederhana kinerja keuangan sesungguhnya bersumber pada kesetiaan pelanggan. Pelanggan yang setia dapat menghemat biaya hingga empat sampai lima kali dibandingkan biaya yang dikeluarkan untuk mendapatkan pelangan baru. Kenyataan ini menjadi tantangan tersendiri bagi dunia perbankan, yaitu bagaimana menciptakan keinginan pelanggan untuk menggunakan produk dan jasa perusahaan serta menjalin hubungan yang dekat dengan nasabahnya.

Negara Thailand merupakan salah satu negara non-Islam yang sudah memperkenalkan perbankan berbasis syariah yaitu: Thanakhan Islam Haeng Prathed Thai atau Islamic Bank of Thailand. Perbankan syariah ini hanya dipusatkan operasionalnya diwilayah selatan Thailand yaitu: Yala, Pattani, dan Narathiwat. Ketiga provinceinsi tersebut merupakan wilayah kriterial kerajaan Thailand yang didiami oleh mayoritas beragama Islam. Umat Islam secara demografis di negara tersebut jumlahnya cukup kecil, tetapi menjadi begitu penting karena beberapa provinceinsi selatan beragama Islam dan memiliki radikalisme tinggi dan bahkan semangat separatisme (memerdekakan diri) dari Thailand.

Islamic Bank of Thailand yang didirikan di bawah pengawasan Departemen Keuangan dengan modal terdaftar 1,000 juta Bath (1 Bath=Rp300) dan mulai beroperasinya pada bulan Juni 2003 berpusat di kota Bangkok. Kemudian berkembang keseluruh negara hingga akhir tahun 2005 total Islamic Bank of Thailand berjumlah 27 cabang.

Tujuan utama Islamic Bank of Thailand pada tahap awal pelaksanaannya hanya berfokus kepada nasabah Muslim di Thailand, tetapi bank selalu memberikan layanannya menurut konsep Islam yaitu tanpa system riba sehingga dapat memenuhi kebutuhan masyarakat umum tidak hanya terbatas pada masyarakat muslim saja. Sistem ini didasarkan pada kepentingan produk dan jasa bank yang memenuhi kebutuhan nasabah. Meningkatkan rekonstruksi citra dan layanan dengan mempertimbangkan kepentingan terbaik bagi nasabah.

Tanggapan atau sikap masyarakat terhadap bank syariecah cukup beragam, baik mengenai pelayanannya, kemudahan untuk memperoleh akses pendanaan, maupun mengenai produk-produk yang ditawarkan tanpa adanya sistem riba. Oleh karena itu, perkembangan bank syarieah perlu mendapatkan perhatian dari seluruh pihak terkait. Masyarakat adalah salah satu elemen terpenting dalam dunia perbankan, hal ini dikarenakan masyarakatlah yang akan menjadi nasabah bagi bank syari" ah. Oleh karena itu, mengetahui sikap masyarakat terhadap bank syarie'ah menjadi kunci pertama dalam membuka jalan kemajuan bank syarie'ah dan sekaligus sebagai bahan pertimbangan investasi di dunia perbankan syariceah.

Meningkatkan rekonstruksi citra dan layanan dengan mempertimbangkan kepentingan terbaik bagi nasabah. Tanggapan atau sikap masyarakat terhadap bank syariah cukup beragam, baik mengenai pelayanannya, kemudahan untuk memperoleh akses pendanaan, maupun mengenai produk-produk yang ditawarkan. Oleh karena itu, perkembangan bank syariah perlu mendapatkan perhatian dari seluruh pihak terkait. Masyarakat adalah salah satu elemen terpenting dalam dunia perbankan, hal ini dikarenakan masyarakatlah yang akan menjadi nasabah bagi bank syariah. Oleh karena itu, mengetahui sikap masyarakat terhadap bank syariah menjadi kunci pertama dalam membuka jalan kemajuan bank syariah dan sekaligus sebagai bahan pertimbangan investasi di dunia perbankan syariah.

Dari hasil observasi penulis ketahui bahwa jumlah nasabah terus mengalami penurunan. Hal ini dapat dipengaruhi oleh persaingan bank yang ada serta jumlah fasilitas yang disediakan. Permasalahan lain dalam penelitian ini antara lain :

1. Indikator Tangible (bukti langsung), interior bank yang tidak ada pembaharuan dari segi warna bangunan dan bentuk ruangan yang tidak terlalu luas.

2. Indikator Realibility (Kehandalan), kurangnya jumlah karyawan dalam melayani khususnya saat nasabah melakukan transaksi, sehingga harus mengantri dan menunggu lama sehingga dapat berdampak pada kurang optimalnya pelayanan yang diberikan.

3. Indikator Responsivenee (Daya tanggap), masih ada beberapa karyawan yang tidak cepat tanggap terhadap permasalahan yang ditemui pada nasabah sehingga nasabah harus menunggu lama.

4. Indikator Assurance (Jaminan), masih ada beberapa karyawan yang tidak bersikap ramah saat melayani nasabah, hal ini disebabkan faktor kelelahan karena tidak seimbanganya jumlah karyawan yang melayani dengan nasabah yang datang untuk bertransaksi di bank.

5. Indikator Emphaty (Perhatian), kurang tanggapnya karyawan terhadap kebutuhan informasi yang diperlukan nasabah dan dapat berdampak pada ketidakpuasan nasabah tersebut.

Perkembangan dunia perbankan dewasa ini sangatlah pesat. Banyaknya pesaing menyebabkan perusahaan sulit untuk mempertahankan nasabah agar tetap loyal. Banyak pesaing yang memberikan penawaran yang lebih menjanjikan keuntungan kepada nasabah adalah salah satu penyebabnya. Dalam 


\section{SYNERGY}

Jurnal Bisnis dan Manajemen
Vol 1, No 2, Oktober 2021, p. 58-61

e-ISSN : 2777-0346 | p-ISSN : 2777-0354

usaha memenangkan persaingan tersebut, maka pemanfaatan teknologi merupakan hal yang wajib. Peranan teknologi dalam pengembangan dan penyediaan produk baru atau fasilitas pelayanan jasa perbankan sangatlah signifikan. Para pengguna jasa perbankan dimanjakan dengan berbagai fasilitas yang memudahkan mereka untuk melakukan transaksi perbankan, sehingga meningkatkan retensi penggunaan jasa perbankan tersebut. Walaupun nasabah akan dikenakan biaya ekstra untuk pengunaan fasilitas tersebut.

\section{METODE PENELITIAN}

Tipe penelitian yang digunakan dalam peneliitan ini yaitu deskriptif kuantitatif, yaitu mengambarkan keadaan yang sebenarnya tentang apa yang terdapat pada saat penelitian yang berdasarkan pada pengamatan penulis dilapangan dengan cara mengumpulkan data, mengklarifikasikan dan menganalisa sehingga diperoleh rumusan analisa terhadap permasalahan yang dihadapi. Kemudian dengan metode penelitian kuantitatif, metode ini berusaha memberikan suatu gambaran mengenai keadaan dilapangan sehingga metode ini bertujuan mengakumulasi data belaka sehingga diperoleh kesimpulan dari penelitian. Dengan menggunakan rumus Slovin tersebut maka dapat diketahui jumlah sampel pada penelitian ini berjumlah 100 orang nasabah pada Bank. Untuk teknik pengumpulan data digunakan observasi, wawancara, kuesioner dan dokumentasi.

\section{HASIL DAN PEMBAHASAN}

Berdasarkan hasil analisis, maka diperoleh hasil uji t yang diperlukan untuk menguji signifikansi konstanta dan variabel independen. Untuk variabel Tangible (Bukti langsung)( $\left.X_{1}\right)$ nilai signifikannya adalag $0.383>0.05$. Hal ini menunjukkan bahwa Tangible (Bukti langsung) $\left(X_{1}\right)$ tidak berpengaruh terhadap kepuasan nasabah pada Islamic Bank of Thailand Branch Bannangstar Province Yala. Untuk variabel Realibility (Kehandalan) $\left(X_{2}\right)$ nilai signifikannya adalah $0.684>0.05$. Hal ini menunjukkan bahwa Realibility (Kehandalan) $\left(X_{2}\right)$ tidak berpengaruh terhadap kepuasan nasabah pada Islamic Bank of Thailand Branch Bannangstar Province Yala. Untuk variabel Responsivenee (Daya tanggap) $\left(X_{3}\right)$ nilai signifikannya adalah $0.814<0.05$. Hal ini menunjukkan bahwa Responsivenee (Daya tanggap) $\left(X_{3}\right)$ tidak berpengaruh terhadap Kepuasan nasabah pada Islamic Bank of Thailand Branch Bannangstar Province Yala. Untuk variabel Assurance (Jaminan) $\left(X_{4}\right)$ nilai signifikannya adalah $0.001<0.05$. Hal ini menunjukkan bahwa Assurance (Jaminan) $\left(X_{4}\right)$ berpengaruh terhadap Kepuasan nasabah pada Islamic Bank of Thailand Branch Bannangstar Province Yala. Untuk variabel Emphaty (Perhatian) $\left(X_{5}\right)$ nilai signifikannya adalah $0.025<0.05$. Hal ini menunjukkan bahwa Emphaty (Perhatian) $\left(X_{5}\right)$ berpengaruh terhadap Kepuasan nasabah pada Islamic Bank of Thailand Branch Bannangstar Province Yala.

\section{KESIMPULAN}

Berdasarkan hasil pengisian kuisioner oleh para responden penelitian ini mengenai kualitas pelayanan diperoleh kesimpulan nasabah merasa sangat memuaskan dengan kualitas pelayanan yang diberikan pada Islamic Bank of Thailand Branch Bannangstar Province Yala. Kepuasan nasabah juga diperoleh sangat memuaskan karena telah mendapatkan pelayanan yang baik pada Islamic Bank of Thailand Branch Bannangstar Province Yala. Sehingga dari hasil pengolahan data diketahui kualitas pelayanan berpengaruh signifikan terhadap variabel kepuasan konsumen Islamic Bank of Thailand Branch Bannangstar Province Yala.

\section{UCAPAN TERIMAKASIH}

Terimakasih kepada semua pihak yang telah membantu penelitian ini, kepada Dr. Hj. Rosmayani. S.Sos. M.Si yang telah banyak membantu dalam menyelesaikan jurnal ini, kepada ayahnda dan ibunda serta adik-adikku, terima kasih atas curahan kasih sayang, untaian doa, serta motivasi tiada henti dan sangat besar yang tak ternilai harganya bagi penulis. Terima kasih atas semua yang telah engkau berikan, tak akan aku kurangi bakti dan cintaku padamu, dan hanya Allah SWT lah yang mampu membalasnya. 


\section{DAFTAR PUSTAKA}

A.S Moenir, 2008. Manajemen Pelayanan Umum di Indonesia. Bandung: PT. Bumi Aksara.

Akbar M.M and Parvez. 2009. Impact of Service Quality, Trust, and Customer Satisfaction Loyalty, ABAC Journal, Vol. 29, No.1.Januari, 24-38.

Agusty Ferdinanad, 2006, Metode Penelitian Manajemen, Pedoman Penelitian Untuk Penulisan Skripsi, Tesis, Dan Disertasi Ilmu Manajemen, Edisi Ke 2, Badan Penerbit Universitas Diponegoro.

Hardiyansyah. 2011. Kualitas Pelayanan Publik Konsep, Dimensi, Indikator, dan Implementasinya.Yogyakarta:Gava Media.

Ratminto dan Atik, 2005. Manajemen Pelayanan. Jakarta: Pustaka Pelajar.

Syofian Siregar, 2012, Statistika Deskriptif untuk Penelitian Dilengkapi Perhitungan Manual dan Aplikasi SPSS Versi 17. Jakarta: PT. Rajawali Pers.

Susanto, A B. 2007. Reputation Driven Corporate Social Responsibility. Jakarta: Erlangga.

Sugiyono. 2011. Metode Penelitian Bisnis. Cetakan Kedelapan. CV Alfabeta. Bandung.

Tjiptono Fandy, 2014, Service Quality \& Satisfaction, Yogyakarta Penerbit Andi. 